\title{
In Der Henjabranadt.
}

Sditwer bängt Der Sănee an $\mathfrak{A} \mathfrak{t}$ unb 3weigen, Deat tief die wellen Blumen ju;

Ernjt riegt Der $\mathfrak{B a l b}$ in tiefem Sameigen, IIs ifilafe er die ew'ge Rúg.

Boll glängt der Mond, die Sterme funteln In feierlichem \&idigemand, und lang geftrecte Salten bunieln Go geifterfaft am $\mathfrak{B a l}$ aezrand.

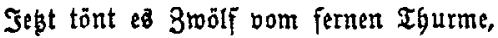
Der 3eiger rŭat in's neue $\mathfrak{s} a \mathfrak{r}$; $6 z$ tobt und trallt in wildem Sturme Im Dorfe los die junge Shaar.

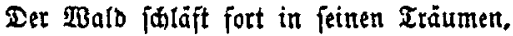
Bom Menjळentreiben unberũđt; -

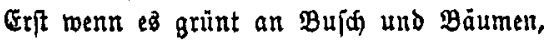
Wird er vom nouen $\mathfrak{s} a \mathfrak{b}$ beglüt.

Dann erft erwaden feine Rieber, Raji) wogt Dann fudt er in ber Tiefé wieder Der Erde frifhen Rebendjaft.

Und triutt in weit gefolten 3 ügen Uuf feiner Freunde Bohlergehn, Die froh in jeinen Shatten liegen, Went fanfte Frügling glüfte regn.

Sh aber trint fdon Geute gerne Uuf aller $\mathfrak{B a a l b e r ~} \mathfrak{B}$ ohlgebei

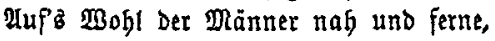
Die ibre Iraft Dem $\mathfrak{2 B a l b e}$ weigrt.

Couarb ஒauโus.

1862. 